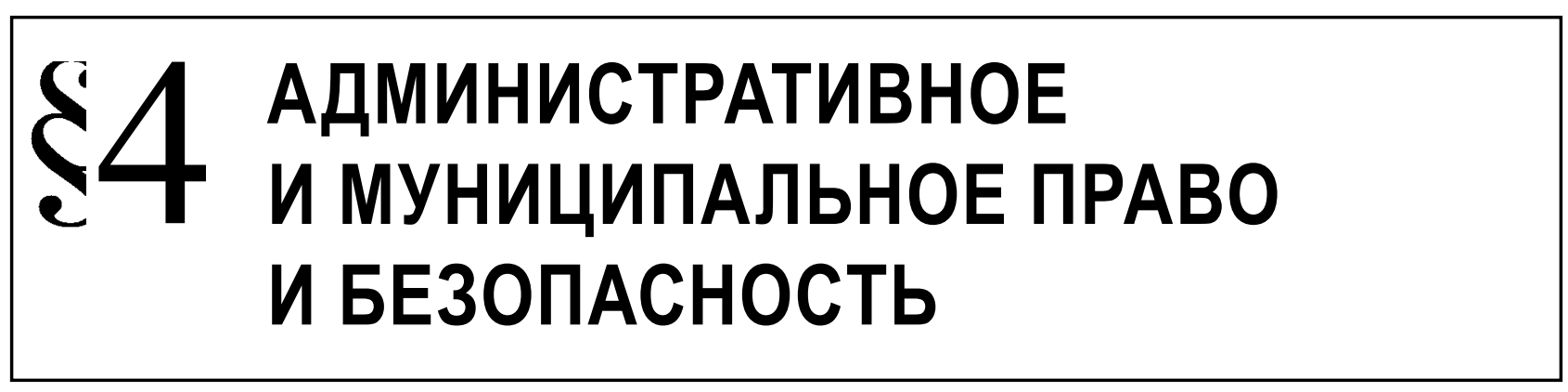

Купреев С.С.

\title{
О СИСТЕМЕ АДМИНИСТРАТИВНО-ПРАВОВЫХ СРЕДСТВ ПРЕДУПРЕЖДЕНИЯ ТЕРРОРИЗМА
}

\begin{abstract}
Аннотация: В условиях нарастания террористической активности, расширения географии терроризма и повышения уровня организованности террористической деятельности существует объективная потребность в повышении эффрективности принимаемых мер по противодействию данному явлению. Как сказано в Концепции противодействия терроризму в Российской Федерации, особая роль в предупреждении терроризма принадлежит реализации предусмотренных законодательством административно-правовых мер. Учитывая возможность гибкой и оперативной реализации норм административного права, преимущественно предупредительный характер таких норм, административно-правовым средствам должна отводиться одна из ведущих ролей среди всего комплекса мер противодействия терроризму. В статье раскрывается система наиболее эффективных на взгляд автора административно-правовых средств предупреждения терроризма, которые могут быть использованы правоохранительными органами и спецслужбами в процессе противодействия террористической деятельности. Построение системы административно-правовых средств предупреждения терроризма осуществлено на основе анализа содержания и практики применения концептуальных документов и нормативных правовых актов, регламентирующих вопросы противодействия терроризму и реализации административно-правовых режимов. В статье построена модель системы наиболее эфреективных административно-правовых средств предупреждения терроризма, удобной для понимания и практического применения. При очевидной потребности в расширении применения административно-предупредительных средств противодействия терроризму систематизация таких правовых средств приобретает особую актуальность и может способствовать более эфрфективной деятельности спецслужбб и правоохранительных органов в рассматриваемой сфере.
\end{abstract}

Ключевые слова: система, административно-правовые средства, предупреждение, терроризм, профилактика, административно-правовые режимы, безопасность, административный надзор, противодействие, террористическая опасность.

Review: In the conditions of terrorist activity increase, its geography expansion and organization enhancement there is an objective need for the increase of effectiveness of preventive measures. As it is stated in the Anti-terrorist strategy of the Russian Federation, the realization of legislative measures is of primary importance in terrorism prevention. Taking into account the possibility of a flexible and quick realization of administrative law provisions and the preventive character of these provisions, administrative-legal measures should be assigned one of the leading parts among the complex of preventive measures. The article reveals the system of the most effective administrative-legal measures of terrorism prevention which can be used by law-enforcement agencies and special services. The proposed system of administrativelegal measures is based on the analysis of content and practice of use of the conceptual documents and legal provisions regulating the issues of terrorism prevention and administrative-legal mechanisms implementation. The author creates an easy-to-use model of the system of the most effective administrative-legal measures of terrorism prevention. Taking into consideration the obvious need for expansion of use of administrative-legal measures of terrorism prevention, the systematization of these legal measures takes of special significance and can promote the effective activities of special services and law enforcement agencies in this sphere.

Keywords: system, administrative-legal measures, prevention, terrorism, prophylaxis, administrative-legal conditions, security, administrative supervision, combating, terrorist threat. 
C тратегия национальной безопасности Российской Федерации до 2020 года ${ }^{1}$ гласит, что Россия при обеспечении национальной безопасности в сфере государственной и общественной безопасности на долгосрочную перспективу исходит из необходимости постоянного совершенствования правоохранительных мер по выявлению, предупреждению, пресечению и раскрытию актов терроризма. Деятельность террористических организаций, группировок и отдельных лиц, направленная на насильственное изменение основ конституционного строя Российской Федерации, дезорганизацию нормального функционирования органов государственной власти (включая насильственные действия в отношении государственных, политических и общественных деятелей) рассматриваются в Стратегии в качестве одного из основных источников угроз национальной безопасности.

В соответствии с Федеральным законом «0 противодействии терроризму»², противодействие терроризму включает в себя три вида деятельности, осуществляемой органами государственной власти и органами местного самоуправления:

а) предупреждение терроризма, в том числе выявление и последующее устранение причин и условий, способствующих совершению террористических актов (профилактика терроризма);

б) выявление, предупреждение, пресечение, раскрытие и расследование террористического акта (борьба с терроризмом);

в) минимизация и (или) ликвидация последствий проявлений терроризма.

Предупреждение терроризма не случайно занимает первое место в указанной триаде: приоритет мер предупреждения терроризма законодательно закреплен в качестве одного из основных принципов противодействия терроризму․․ Предупредительное воздействие играет ключевую роль среди всего комплекса мер, направленных на противодействие террористической деятельности. Как писал один из классиков юридической науки Чезаре Беккариа, «лучше предупреждать преступления, чем наказывать. В этом - главная цель

\footnotetext{
1 Утверждена Указом Президента Российской Федерации от 12 мая 2009 года № 537.

2 См. Федеральный закон от 6 марта 2006 года № 35-Ф3 «О противодействии терроризму».

3 См. ст. 2 Федерального закона «О противодействии терроризму».
}

всякого хорошего законодательства...» ${ }^{4}$. Похожую мысль высказывал позже Ф.Э. Дзержинский: по его словам, предупреждение преступлений в смысле внешнего эффекта производит меньше впечатления, чем карательные меры, но по существу дает несравненно большие результаты ${ }^{5}$.

Как говорится в Концепции противодействия терроризму в Российской Федерации ${ }^{6}$, особая роль в предупреждении терроризма принадлежит эффективной реализации предусмотренных законодательством административно-правовых мер. Учитывая возможность гибкой и оперативной реализации норм административного права, преимущественно предупредительный характер таких норм, административно-правовым средствам должна отводиться одна из ведущих ролей среди всего комплекса мер противодействия терроризму. В данной статье раскрывается система наиболее эффективных на взгляд автора административно-правовых средств предупреждения терроризма, которые могут быть использованы правоохранительными органами и спецслужбами в процессе противодействия террористической деятельности.

Предупреждение терроризма с точки зрения своего содержания является довольно объемным понятием и подразумевает реализацию целого комплекса правовых средств (в том числе административно-правовых), с помощью которых осуществляется воздействие на общественные процессы в целом, а также на организации и отдельных граждан. В связи с этим представляется необходимым сгруппировать административноправовые средства предупреждения терроризма по отдельным блокам (группам) в целях приведения их в систему, удобную для понимания и практического применения.

Первую группу составляют административно-правовые средства предупреждения терроризма, являющиеся частью общегосударственной системы противодействия терроризму. Речь идет, прежде всего, о правовом закреплении уровней террористической опасности, предусматривающих принятие дополнительных мер по обеспечению безопасности личности, общества и государства, а также системы требований, обеспечивающих

\footnotetext{
4 Беккариа Ч. О преступлениях и наказаниях. - М.: Инфра-М, 2011. С. 150.

5 См.: Ф.Э. Дзержинский - председатель ВЧК-ОГПУ: сб. документов (1917-1926 гг.). - М.: Молодая гвардия, 1977. С. 65.

6 Утверждена Президентом РФ 5 октября 2009 года.
} 
антитеррористическую защищенность объектов (территорий).

В соответствии со ст. 5 Федерального закона «0 противодействии терроризму», в целях своевременного информирования населения о возникновении угрозы террористического акта и организации деятельности по противодействию его совершению, могут устанавливаться уровни террористической опасности, предусматривающие принятие не ограничивающих прав и свобод человека и гражданина дополнительных мер по обеспечению безопасности личности, общества и государства ${ }^{7}$. На отдельных участках территории Российской Федерации (объектах) могут устанавливаться следующие уровни террористической опасности:

а) повышенный («синий») - при наличии требующей подтверждения информации о реальной возможности совершения террористического акта;

б) высокий («желтый») - при наличии подтвержденной информации о реальной возможности совершения террористического акта;

в) критический («красный») - при наличии информации о совершенном террористическом акте либо о совершении действий, создающих непосредственную угрозу террористического акта.

Решение об установлении, изменении или отмене уровней террористической опасности в субъекте Российской Федерации принимает председатель антитеррористической комиссии по согласованию с руководителем территориального органа безопасности. Уровень террористической опасности может устанавливаться на срок не более 15 суток. В соответствии с установленным уровнем террористической опасности могут приниматься дополнительные меры по обеспечению безопасности личности, общества и государства, например, дополнительный инструктаж нарядов полиции и отдельных категорий военнослужащих, а также персонала и подразделений потенциальных объектов террористических посягательств, выставление в общественных местах усиленных патрулей, в том числе с привлечением специалистов кинологической службы; усиление контроля в ходе проведения досмотровых мероприятий на объектах транспорта с использованием специальных технических средств.

\footnotetext{
Порядок установления уровней террористической опасности и содержание дополнительных мер установлены Указом Президента Российской Федерации от 14 июня 2012 года № 851 .
}

В конце 2013 года Правительством Российской Федерации утверждены Правила разработки требований к антитеррористической защищенности объектов (территорий) и паспорта безопасности объектов (территорий) ${ }^{8}$. Указанные Правила устанавливают порядок разработки требований к антитеррористической защищенности объектов (территорий) (за исключением объектов транспортной инфраструктуры, транспортных средств и объектов топливно-энергетического комплекса) и паспорта безопасности объектов (территорий). Требования и формы паспорта безопасности разрабатываются МВД России ${ }^{9}$, федеральными органами исполнительной власти и Государственной корпорацией по атомной энергии «Росатом» ${ }^{10}$ по согласованию с ФСБ России.

В требованиях, в частности, должны содержаться меры, направленные:

a) на воспрепятствование неправомерному проникновению на объект (территорию);

б) на выявление потенциальных нарушителей установленного на объекте (территории) режима и (или) признаков подготовки или совершения террористического акта;

в) на пресечение попыток совершения террористического акта на объекте (территории);

г) на минимизацию возможных последствий и ликвидацию угрозы террористического акта на объекте (территории).

Вторую группу административно-правовых средств предупреждения терроризма составляют меры профилактики терроризма. Профилактика включает в себя выявление, устранение, локализацию факторов, способствующих совершению

\footnotetext{
8 См. постановление Правительства Российской Федерации от 25 декабря 2013 года № 1244 «Об антитеррористической защищенности объектов (территорий)».

9 МВД России осуществляет разработку требований и формы паспорта безопасности в отношении мест массового пребывания людей и объектов (территорий), не относящихся к сфере деятельности других федеральных органов исполнительной власти или Государственной корпорации по атомной энергии «Росатом» и подлежащих обязательной охране полицией.

10 Федеральные органы исполнительной власти и Государственная корпорация по атомной энергии «Росатом» осуществляют разработку требований и формы паспорта безопасности в отношении объектов (территорий), правообладателями которых они являются или которые относятся к сфере их деятельности, предполагающей использование объекта (территории), подлежащего антитеррористической защите (за исключением объектов, подлежащих обязательной охране полицией).
} 
преступлений или нейтрализацию их действия, а также корректирующее антикриминогенное воздействие на лиц, динамика поведения которых свидетельствует о возможном совершении ими преступления ${ }^{11}$.

Российское административное право предусматривает как меры индивидуальной профилактики, так и меры профилактики, применяемые в отношении организаций. В частности, Федеральным законом «0 федеральной службе безопасности» предусмотрена возможность объявления лицу обязательного для исполнения официального предостережения о недопустимости действий, создающих условия для совершения преступлений, дознание и предварительное следствие по которым отнесено законодательством РФ к ведению органов федеральной службы безопасности, при отсутствии оснований для привлечения к уголовной ответственности. Указанный институт активно применялся в советское время и был возрожден на законодательном уровне в 2010 году ${ }^{12}$. С учетом того, что официальное предостережение непосредственно затрагивает права и свободы граждан, закон закрепляет четкие требования к процедуре его объявления. Конкретный порядок объявления официального предостережения установлен приказом ФСБ России от 2 ноября 2010 г. № $544^{13}$.

Федеральным законом «О федеральной службе безопасности» ${ }^{14}$ также предусмотрено право органов федеральной службы безопасности вносить в государственные органы, администрации пред-

11 См.: Терроризм в современном мире. 2-изд. / под ред. В.Л. Шульца; Центр исслед. проблем безопасности РАН. М.: Наука, 2011. С. 324.

12 См. Федеральный закон от 27 июля 2010 года № 238-Ф3 «О внесении изменений в Федеральный закон «О федеральной службе безопасности» и в Кодекс Российской Федерации об административных правонарушениях».

13 В частности, приказом установлено, что основанием для объявления официального предостережения являются достаточные и в обязательном порядке предварительно подтвержденные сведения о конкретных действиях физического лица, создающих условия для совершения преступлений: проявляющих вовне (словесно, письменно или иным образом) намерения совершить определенное преступление при отсутствии признаков приготовления к преступлению или покушения на преступление;

образующих приготовление к преступлениям небольшой и средней тяжести либо непосредственно направленных на совершение таких преступлений при отсутствии признаков покушения.

14 См. пункт «л)» статьи 13 и статью 131 Федерального закона «О федеральной службе безопасности». приятий, учреждений и организаций независимо от форм собственности, а также в общественные объединения обязательные для исполнения представления об устранении причин и условий, способствующих реализации угроз безопасности Российской Федерации, совершению преступлений, дознание и предварительное следствие по которым отнесены законодательством к их ведению ${ }^{15}$.

Внесение указанных представлений осуществляется при наличии достаточных данных, выявленных в процессе оперативно-служебной деятельности органов безопасности и указывающих на наличие причин и условий, способствующих реализации угроз безопасности государства ${ }^{16}$, имеет значительное профилактическое действие, позволяет своевременно предотвратить совершение преступлений, в том числе связанных с осуществлением террористической деятельности ${ }^{17}$.

Учитывая то обстоятельство, что террористическая деятельность является одной из форм экстремисткой деятельности, значительный профилактический потенциал имеет применение норм Федерального закона «О противодействии экстремисткой деятельности» ${ }^{18}$. Статья 6 данного Закона предусматривает возможность при наличии достаточных и предварительно подтвержденных сведений о готовящихся противоправных действиях, содержащих признаки экстремистской деятельности, и при отсутствии оснований для привлечения к уголовной ответственности направления руководителю общественного или религиозного объединения либо иной организации, а также другим соответствующим лицам предостережения в письменной форме о недопустимости такой

15 Порядок внесения представлений установлен приказом ФСБ России от 13 марта 2004 года № 162 «О внесении представлений органами федеральной службы безопасности».

16 При определении угроз безопасности необходимо руководствоваться положениями Федерального закона «О безопасности», Стратегии национальной безопасности Российской Федерации до 2020 года и иными нормативными правовыми актами Российской Федерации, документами стратегического планирования и доктринами, определяющими угрозы безопасности Российской Федерации, утвержденными Президентом Российской Федерации.

17 Подробнее об этом см., например: Купреев С. С., Дорофеев Р. О. Административно-правовые средства профилактики преступлений, применяемые в сфере обеспечения государственной безопасности // Полицейская деятельность. - 2013. - № 2 .

18 См. Федеральный закон от 25 июля 2002 года № 114-Ф3 «О противодействии экстремисткой деятельности». 
деятельности с указанием конкретных оснований объявления предостережения ${ }^{19}$. В случае невыполнения требований, изложенных в предостережении, лицо, которому было объявлено данное предостережение, может быть привлечено к ответственности в установленном порядке.

В условиях, когда приоритетность применения профилактических мер закреплена в основных законодательных актах, регулирующих вопросы обеспечения безопасности и противодействия экстремизму и терроризму, применение административно-правовых средств профилактики преступлений террористической направленности имеет ключевое значение. Посредством реализации указанных мер оказывается оперативное и в то же время юридически властное воздействие на негативные процессы, которые впоследствии могут перерасти в серьезные противоправные деяния, что очевидно является необходимой предпосылкой функционирования действенной системы противодействия терроризму.

Третью группу административно-правовых средств предупреждения терроризма образуют правовые нормы и организационные меры, предусмотренные соответствующими административно-правовыми режимами. Наибольшую роль в предупреждении терроризма играют режим въезда в РФ и выезда из РФ, режим пребывания иностранцев в РФ, паспортная система, лицензионно-разрешительная система, режим обеспечения безопасности объектов транспорта, в частности, гражданской авиации.

Применение законодательства, устанавливающего правовое положение иностранцев ${ }^{20}$, позволяет исключать или максимально затруднять осуществление иностранцами, в том числе членами международных террористических организаций, террористической деятельности на территории России. Иностранцу может быть не разрешен въезд РФ без объяснения причин, если это необходимо в целях обеспечения обороноспособности или безопасности государства, либо общественного порядка, либо защиты здоровья населения. В от-

\footnotetext{
19 Предостережение направляется Генеральным прокурором РФ или его заместителем либо подчиненным ему соответствующим прокурором или его заместителем.

20 См., например, Федеральный закон от 15 августа 1996 года № 114-Ф3 «О порядке выезда из Российской Федерации и въезда в Российскую Федерацию», Федеральный закон от 25 июля 2002 года № 115-Ф3 «О правовом положении иностранных граждан в Российской Федерации».
}

ношении иностранцев, находящихся в РФ, может быть принято решение о нежелательности их пребывания в России. Им также может быть отказано в выдаче либо аннулировано разрешение на временное проживание или вид на жительство, если они финансируют, планируют террористические (экстремистские) акты, оказывают содействие в совершении таких актов или совершают их, иными действиями поддерживают террористическую (экстремистскую) деятельность. Важное значение в предупреждении террористической деятельности иностранцев имеет также осуществление миграционного учета ${ }^{21}$.

Реализация паспортной системы ${ }^{22}$ позволяет спецслужбам и правоохранительным органам в максимально короткие сроки осуществлять розыск лиц, в отношении которых имеются данные об их намерении совершить действия террористического характера, за счет использования данных соответствующих учетов граждан, прежде всего данных регистрации граждан по месту жительства и по месту пребывания, данных транспортных организаций о передвижениях лиц, а также за счет проверки документов, удостоверяющих личность граждан.

Так, в частности, при высоком («желтом») уровне террористической опасности (наряду с мерами, принимаемыми при установлении повышенного («синего») уровня) подлежит усилению контроль за соблюдением российскими гражданами, в том числе должностными лицами, порядка регистрации и снятия с регистрационного учета по месту их пребывания и по месту жительства, а также за соблюдением иностранцами порядка пребывания и проживания в России, въезда, выезда и транзитного проезда через территорию страны ${ }^{23}$.

21 См. Федеральный закон от 18 июля 2006 года № 109-Ф3 «О миграционном учете иностранных граждан и лиц без гражданства в Российской Федерации».

22 Понятие паспортной системы образуют несколько групп правовых норм, в частности:

правовые нормы, устанавливающие документы, удостоверяющие личность гражданина РФ; правовые нормы, устанавливающие содержание паспорта гражданина РФ, порядок его выдачи и замены;

правовые нормы, регулирующие порядок регистрации граждан РФ по месту пребывания и по месту жительства и снятия их с регистрационного учета.

23 См. Указ Президента Российской Федерации от 14 июня 2012 года № 851 «О порядке установления уровней террористической опасности, предусматривающих принятие дополнительных мер по обеспечению безопасности личности, общества и государства». 
В рамках лицензионно-разрешительной системы наибольшую роль в деле предупреждения терроризма играет режим оборота оружия и боеприпасов ${ }^{24}$, включающий, в частности, правила оборота оружия, ограничения, устанавливаемые на его оборот, лицензионный порядок приобретения оружия и патронов к нему, контрольный отстрел из огнестрельного оружия с нарезным стволом, а также контроль за оборотом оружия и ведение учетов оружия.

Режим обеспечения безопасности объектов транспорта (авиационного, железнодорожного, водного) выступает одним из наиболее эффективных правовых средств, позволяющих осуществлять предупреждение террористической деятельности, минимизировать вероятность совершения террористических актов и провоз потенциально опасных предметов и веществ на объектах транспорта. Так, в рамках обеспечения авиационной безопасности Воздушным кодексом $Р \Phi^{25}$ и принятыми на его основе правовыми актами ${ }^{26}$ предусмотрены: установление особого пропускного режима в аэропортах; требования к оснащению воздушного судна; правила продажи и оформления билетов и предполетной регистрации пассажиров. Важную роль в обеспечении авиационной безопасности выполняет предполетный и послеполетный досмотр пассажиров и багажа, в том числе вещей, находящихся при пассажирах, членов экипажей воздушных судов, авиационного персонала гражданской авиации, бортовых запасов воздушного судна, грузов и почты ${ }^{27}$.

В качестве одного из наиболее действенных административно-правовых средств предупреждения терроризма необходимо рассматривать административный надзор за лицами, освобожденными из мест лишения свободы. Согласно Федеральному закону «Об административном надзоре за лицами,

\footnotetext{
24 Законодательную основу указанного административноправового режима составляет Федеральный закон от 13 декабря 1996 года № 150-ФЗ «Об оружии».

25 См. Воздушный кодекс Российской Федерации от 19 марта 1997 года № 60-Ф3.

26 См. постановление Правительства Российской Федерации от 30 июля 1994 года № 897 «О федеральной системе обеспечения защиты деятельности гражданской авиации от актов незаконного вмешательства», приказ Минтранса России от 28 ноября 2005 года № 142 «Об утверждении Федеральных авиационных правил «Требования авиационной безопасности к аэропортам».

27 См. Правила проведения предполетного и послеполетного досмотров, утвержденные приказом Минтранса России от 25 июля 2007 года № 104.
}

освобожденными из мест лишения свободы» ${ }^{28}$, административный надзор устанавливается судом для предупреждения совершения поднадзорными лицами преступлений и других правонарушений, оказания на них индивидуального профилактического воздействия в целях защиты государственных и общественных интересов и заключается в применении к поднадзорным лицам определенных административных ограничений ${ }^{29}$ и в осуществлении органами внутренних дел наблюдения за соблюдением лицами, освобожденными из мест лишения свободы, установленных временных ограничений ${ }^{30}$.

Выбор конкретных административных ограничений не может носить произвольный характер, их применение должно быть направлено на обеспечение индивидуального профилактического воздействия. В частности, судом учитываются характер и степень общественной опасности совершенного поднадзорным лицом преступления (преступлений), его поведение за весь период отбывания наказания и поведение после освобождения из мест лишения свободы, семейное положение указанного лица, место и график его работы и (или) учебы, состояние здоровья, а также иные заслуживающие внимания обстоятельства ${ }^{31}$.

28 См. Федеральный закон от 6 апреля 2011 года № 64-Ф3 «Об административном надзоре за лицами, освобожденными из мест лишения свободы».

29 К таким ограничениям относятся:

запрещение пребывания в определенных местах;

запрещение посещения мест проведения массовых и иных мероприятий и участия в указанных мероприятиях;

запрещение пребывания вне жилого или иного помещения, являющегося местом жительства либо пребывания поднадзорного лица, в определенное время суток;

запрещение выезда за установленные судом пределы территории;

обязательная явка от одного до четырех раз в месяц в орган внутренних дел по месту жительства или пребывания для регистрации.

30 Подробнее об административном надзоре за лицами, освобожденными из мест лишения свободы, см., например: Фильченко А. П. Административный надзор за лицами, освобожденными из мест лишения свободы: правовая природа и перспективы законодательного регулирования // Административное право и процесс. - 2012. - № 2; Биюшкина Н. И. Проблемы правового регулирования административного надзора в РФ // Административное и муниципальное право. - 2014. - № 9.

31 См. п. 22. постановления Пленума Верховного Суда РФ от 27 июня 2013 года № 22 «О применении судами законодательства при рассмотрении дел об административном надзоре». 
Важность и даже приоритетность применения административно-правовых средств предупреждения терроризма на сегодняшний день очевидна. В частности, в том числе благодаря эффективному применению таких мер нашей стране удалось обеспечить наивысший уровень безопасности проведения крупных международных мероприятий в течение 2012-2014 годов, в том числе Олимпийских зимних игр в г. Сочи.

В условиях нарастания международной напряженности, террористических и экстремистских проявлений система административно-правовых средств предупреждения терроризма постоянно развивается. Только в 2014 г. введена административная ответственность юридических лиц за оказание финансовой поддержки терроризму ${ }^{32}$, специальные службы наделены правом проверять у лиц документы, удостоверяющие их личность, осуществлять их личный досмотр и досмотр находящихся при них вещей, досмотр транспортных средств и находящихся в них грузов ${ }^{33}$ в целях предотвращения террористических актов. Естественно, обозначенная нами система административноправовых средств предупреждения терроризма не может претендовать на исключительную полноту и строго ограничиваться обозначенными группами правовых средств. Вместе с тем, при очевидной потребности в расширении применения административно-предупредительных средств противодействия терроризму систематизация таких правовых средств приобретает особую актуальность и может способствовать более эффективной деятельности спецслужб и правоохранительных органов в рассматриваемой сфере.

\section{Библиография:}

1. Беккариа Ч. О преступлениях и наказаниях. - М.: Инфра-М, 2011.

2. Биюшкина Н.И. Проблемы правового регулирования административного надзора в РФ // Административное и муниципальное право. - 2014. - № 9.

3. Григорян В.К. Предупреждение преступности в высокоразвитых зарубежных странах // Актуальные проблемы российского права. - 2012. - №

4. Криминология: учебник для вузов / под общ. ред. А.И. Долговой. - М.: Норма, 2007.

5. Кудрявцев В.Н. Стратегии борьбы с преступностью. 2-е изд., испр. и доп. - М.: Наука, 2005.

6. Купреев С.С., Дорофеев Р.О. Административно-правовые средства профилактики преступлений, применяемые в сфере обеспечения государственной безопасности // Полицейская деятельность. - 2013. - № 2.

7. Лозбяков В.П., Овчинский С.С. Административно-правовые меры предупреждения преступлений. - М.: Юридическая литература, 1978.

8. Редкоус В.М. Теоретические проблемы применения института официального предостережения в области обеспечения национальной безопасности // Административное и муниципальное право. - 2013. - № 4.

9. Силаева Н.А. Правовые аспекты предупреждения преступлений, посягающих на политическую систему России // Национальная безопасность / nota bene. - 2013. - № 1.

10. Тищенко В.Н. К вопросу о совершенствовании предупреждения преступности в современных условиях // Национальная безопасность / nota bene. - 2014. - № 1 .

11. Терроризм в современном мире. 2-изд. / под ред. В.Л. Шульца; Центр исслед. проблем безопасности РАН. - М.: Наука, 2011.

12. Ф.Э. Дзержинский - председатель ВЧК-ОГПУ: сб. документов (1917-1926 гг). - М.: Молодая гвардия, 1977.

13. Фильченко А. П. Административный надзор за лицами, освобожденными из мест лишения свободы: правовая природа и перспективы законодательного регулирования // Административное право и процесс. - 2012. № 2 .

14. Фризен П.Д., Газилов Д.А. Административно-правовое предупреждение отдельных видов преступлений: монография. - Барнаул: Изд-во Алтайского университета, 2004

15. А.И. Арестов, П.Н. Кобец Профилактический потенциал административно- правовых средств и их роль в предупреждении преступности // Административное и муниципальное право. - 2011. - 6. - С. 85 - 90.

\section{References (transliterated):}

1. Bekkaria Ch. O prestupleniyakh i nakazaniyakh. - M.: Infra-M, 2011.

2. Biyushkina N.I. Problemy pravovogo regulirovaniya administrativnogo nadzora v RF // Administrativnoe i munitsipal'noe pravo. - 2014. - № 9.

32 См. ст. 15.27.1 Кодекса Российской Федерации об административных правонарушениях от 30 декабря 2001 года № 195-Ф3.
33 См. ст. 1 Федерального закона от 5 мая 2014 года № 130Ф3 «О внесении изменений в отдельные законодательные акты Российской Федерации». 
3. Grigoryan V.K. Preduprezhdenie prestupnosti v vysokorazvitykh zarubezhnykh stranakh // Aktual'nye problemy rossiiskogo prava. - 2012. - №

4. Kriminologiya: uchebnik dlya vuzov / pod obshch. red. A.I. Dolgovoi. - M.: Norma, 2007.

5. Kudryavtsev V.N. Strategii bor'by s prestupnost'yu. 2-e izd., ispr. i dop. - M.: Nauka, 2005.

6. Kupreev S.S., Dorofeev R.O. Administrativno-pravovye sredstva profilaktiki prestuplenii, primenyaemye v sfere obespecheniya gosudarstvennoi bezopasnosti // Politseiskaya deyatel'nost'. - 2013. - № 2.

7. Lozbyakov V.P., Ovchinskii S.S. Administrativno-pravovye mery preduprezhdeniya prestuplenii. - M.: Yuridicheskaya literatura, 1978.

8. Redkous V.M. Teoreticheskie problemy primeneniya instituta ofitsial'nogo predosterezheniya v oblasti obespecheniya natsional'noi bezopasnosti // Administrativnoe i munitsipal'noe pravo. - 2013. - № 4.

9. Silaeva N.A. Pravovye aspekty preduprezhdeniya prestuplenii, posyagayushchikh na politicheskuyu sistemu Rossii // Natsional'naya bezopasnost' / nota bene. - 2013. - № 1 .

10. Tishchenko V.N. K voprosu o sovershenstvovanii preduprezhdeniya prestupnosti v sovremennykh usloviyakh // Natsional'naya bezopasnost' / nota bene. - 2014. - № 1.

11. Terrorizm v sovremennom mire. 2-izd. / pod red. V.L. Shul'tsa; Tsentr issled. problem bezopasnosti RAN. - M.: Nauka, 2011.

12. F.E. Dzerzhinskii - predsedatel' VChK-OGPU: sb. dokumentov (1917-1926 gg.). - M.: Molodaya gvardiya, 1977.

13. Fil'chenko A. P. Administrativnyi nadzor za litsami, osvobozhdennymi iz mest lisheniya svobody: pravovaya priroda i perspektivy zakonodatel'nogo regulirovaniya // Administrativnoe pravo i protsess. - 2012. - № 2.

14. Frizen P.D., Gazilov D.A. Administrativno-pravovoe preduprezhdenie otdel'nykh vidov prestuplenii: monografiya. Barnaul: Izd-vo Altaiskogo universiteta, 2004

15. A.I. Arestov, P.N. Kobets Profilakticheskii potentsial administrativno- pravovykh sredstv i ikh rol' v preduprezhdenii prestupnosti // Administrativnoe i munitsipal'noe pravo. - 2011. - 6. - C. 85 - 90. 